\title{
In-Situ SEM Study of Mechanical Properties of Aluminide Bond Coating at Elevated Temperature
}

\author{
Sanjit Bhowmick ${ }^{1}$, Zafir Alam ${ }^{2}$ and S. A. Syed Asif ${ }^{1}$ \\ ${ }^{1 .}$ Hysitron, Inc., Minneapolis, Minnesota, USA \\ 2. Defense Metallurgical Research Laboratory, Hyderabad, India
}

Diffusion aluminide bond coats are compositionally and microstructurally graded material with significant variation of engineered mechanical properties across the cross-section. Bond coating exhibits three-layered microstructure: (a) outer layer contains intermetallic $\mathrm{PtAl}_{2}$ and $\mathrm{W}$ and $\mathrm{Cr}$-rich fine precipitates, (b) intermediate layer contains $\mathrm{B} 2-(\mathrm{Ni}, \mathrm{Pt}) \mathrm{Al}$ and (c) inner layer is interdiffusion zone containing coarse precipitates in $\mathrm{B} 2-\mathrm{NiAl}$ matrix. This study focused at understanding deformation mechanisms and the variation in mechanical properties as a function of temperature. In-situ SEM nanomechanical instrument, PI 87xR SEM PicoIndenter (Hysitron, Inc., Minneapolis, USA) with an integrated high-temperature stage and an active tip heating was used to conduct uniaxial compression of pillar samples. In-situ mechanical testing allows for precise alignment of the tip with the sample as well as direct, real-time observation of the deformation processes. A side benefit of performing these tests in the SEM is that the high vacuum environment limits the oxidation of the sample, especially at high temperatures, enabling the measurement of the true mechanical properties of the bond coating and superalloy materials. Water circulation through cooling blocks at the sample heater and transducer minimizes thermal drift of the system.

Micropillars of dimensions $8 \mu \mathrm{m} \times 8 \mu \mathrm{m}$ in cross-section and $25 \mu \mathrm{m}$ in height were prepared from the outer layer of PtNiAl coating and Ni-base superalloy region by focused ion beam (FIB). In-situ quasistatic uniaxial compression experiments were conducted with a 20 micrometer flat punch diamond probe. Using the displacement-controlled feedback mode of the system, the pillars were compressed to $5-12 \%$ strain at a strain rate of $10^{-3} \mathrm{~s}^{-1}$. Compression tests were conducted at room temperature (RT) as well as several elevated temperatures up to $800^{\circ} \mathrm{C}$. Heating was achieved through closed-loop resistive heating of both the probe and sample. Tilt and rotation in sample motion allows flexibility in pillar alignment with respect to flat punch probe.

The microstructure of the pillar surface after uniaxial compression of bond coating and superalloy are shown in fig. 1. Fig. 2 displays stress-strain curves which are calculated from load-displacement data. The stress-strain curves of bond coating indicate that plasticity is characterized by major strain hardening after yielding at RT and limited strain hardening at higher temperature. The surface of the bond coating pillars shows grain boundary sliding at higher temperature. It has been calculated that elastic moduli of the bond coating remain nearly constant at RT to $800^{\circ} \mathrm{C}$ whereas yield stress of the coating decreases to $\sim 50 \%$. Transgranular fracture appears on the pillar surface at higher strain at room temperature whereas intergranular fracture dominates deformation at higher temperature.

Load-displacement curves plotted in figure $2 \mathrm{~b}$ show larger load drops in superalloy samples. Figure 1c and $\mathrm{d}$ indicate that load drops are associated with the formation of slip bands. A large number slip bands with bigger step size can be observed on the pillar surface at $600^{\circ} \mathrm{C}$. At $600^{\circ} \mathrm{C}$ the yield strength of superalloy sample decreased by $\sim 20 \%$ compared to room temperature. In summary, uniform plastic deformation without slip bands were observed in Pt-rich layer of bond coating. Grain boundary siding 
predominantly controlled plastic deformation. In contrast, multiple slip bands were observed in Ni-base superalloy. The density and severity of the slip banding increased with temperature.

\section{References:}

[1] B. Jaya et al, J. Mater. Res. 30 (2015) 3343.

[2] B. Jaya et al, Phil. Mag., 95 (2015) 1946.

[3] M. D. Alam et al, Acta Mat., 61 (2013) 1093.

[4] M. D. Alam et al, Acta Mat., 67 (2014) 278.
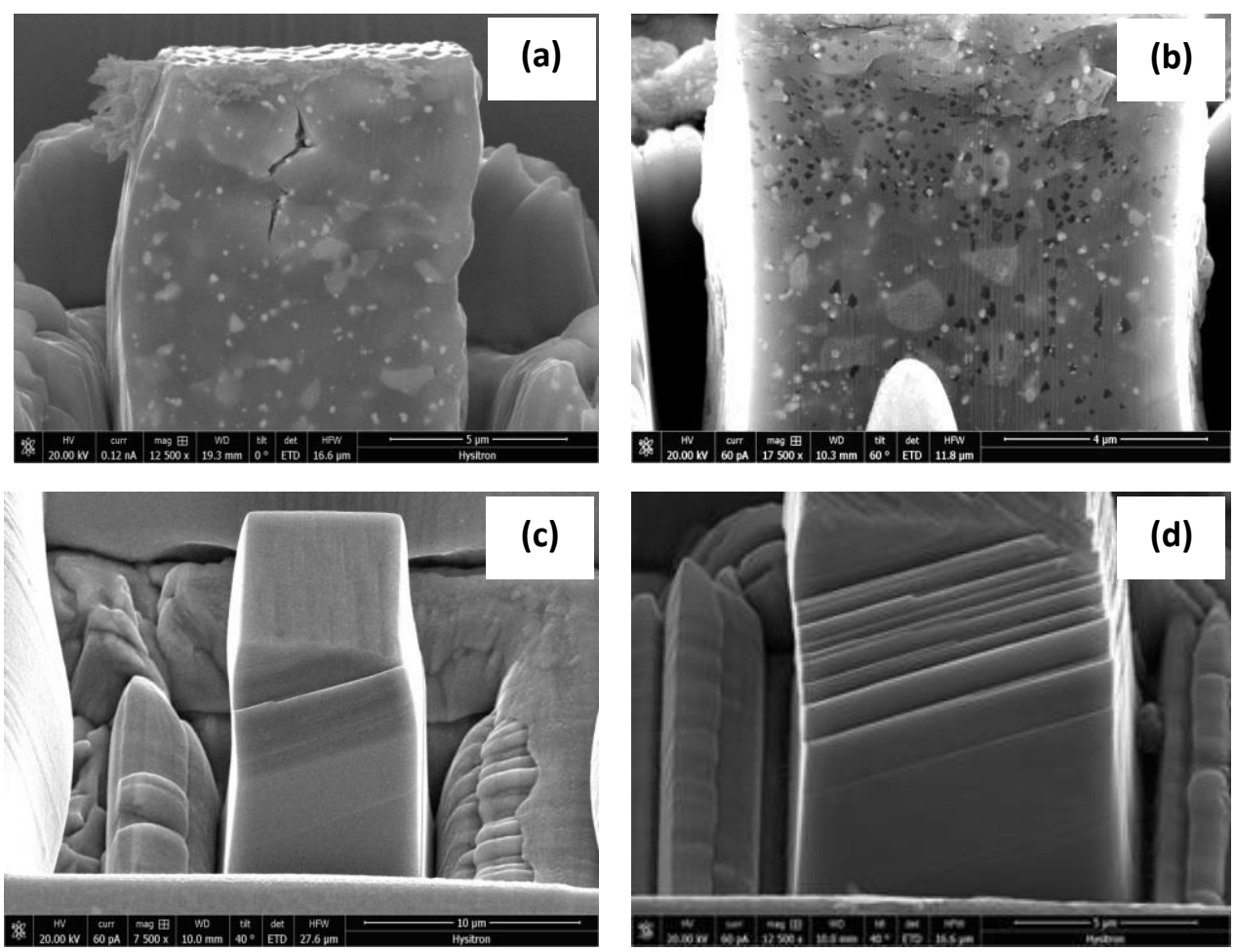

Figure 1. Morphology of the pillars after compression at (a) bond coating at RT, (b) bond coating at $800^{\circ} \mathrm{C}$, (c) superalloy at RT and (d) superalloy at $600^{\circ} \mathrm{C}$.
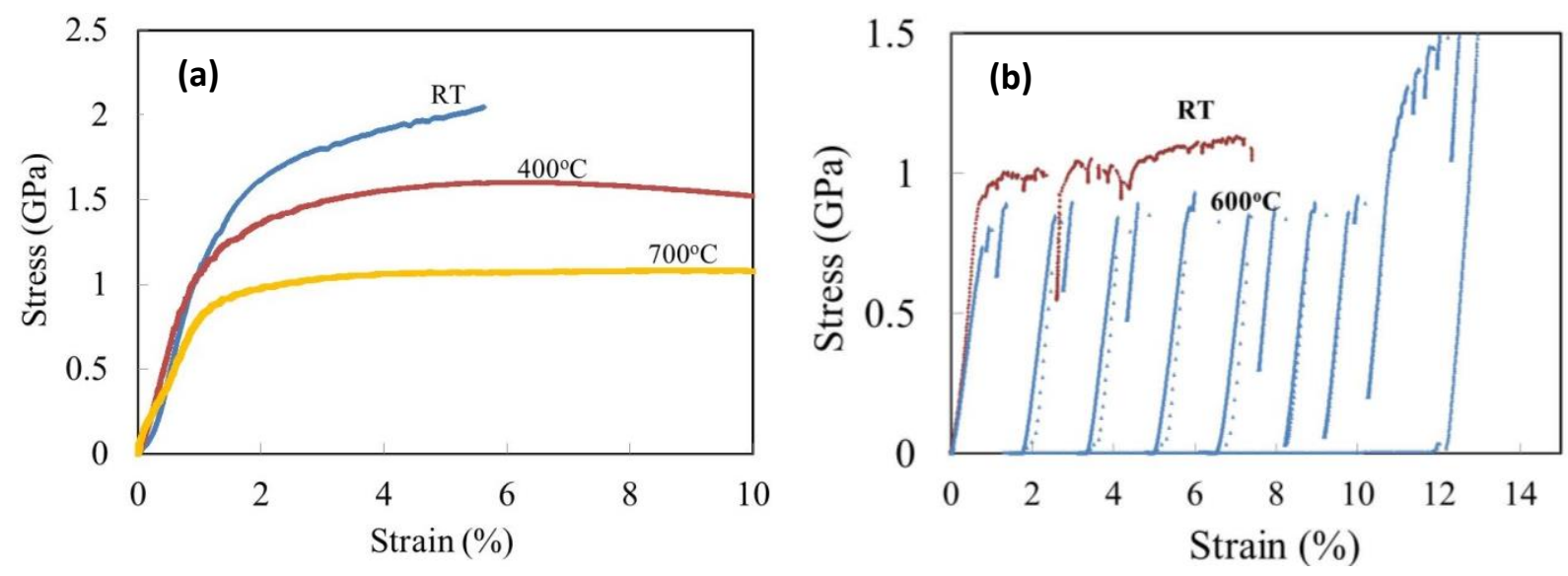

Figure 2. Stress-strain curves of (a) bond coating and (b) Ni-base superalloy. 